\title{
L'APORTACIÓ DE MARIA JESÚS RUBIERA a LA CATALANíSTICA
}

\author{
Rafael ALEMANY FERRER \\ Universitat d'Alacant
}

\section{Les claus d'una línia de recerca}

En un món cada vegada més inexorablement orientat cap a la hiperespecialització i la compartimentació del saber, causa una certa sorpresa - almenys d'un primer cop d'ull - topar-nos amb una arabista com Maria Jesús Rubiera, un nombre important de publicacions de la qual, tot $i$ que sempre relacionades amb l'arabisme, el trascendeixen pel fet que s'endinsen en ambits d'estudi propis de la filologia romànica i, més en particular, de la filologia catalana.

Crec no equivocar-me en afirmar que aquest interés de la nostra estudiosa madrilenya per temes i qüestions de la llengua i literatura catalanes s'inicia arran de la seua incorporació a la Universitat d'Alacant, l'any 1982, després d'una experiència acadèmica prèvia a la Universitat Complutense de Madrid.

Sense pretendre negar altres possibles motivacions anteriors, em sembla fora de dubte que l'establiment de la professora Rubiera en terres alacantines li va obrir unes noves i prometedores expectatives de recerca, derivades, en bona part, del descobriment directe de l'especificitat lingüística i cultural valenciana, fruit en tants aspectes d'una llarga interacció entre l'element aràbigo-musulmà i el cristiano-catalanoaragonés. Res més noble per part de la nostra il·lustre col-lega que posar els seus sabers d'arabista al servei d'un millor coneixement de la realitat lingüística i literària del País Valencià que la acollia. Tanmateix, i per fortuna, un plantejament d'aquest tipus implicava, recíprocament 
i indefectible, una progressiva impregnació per part de la professora Rubiera d'aquells ingredients culturals valencians aliens a la tradici 6 àrab, entre els quals, sense dubte, la llengua i literatura catalanes ocupen un lloc d'especial relleu.

Però encara cal afegir alguna cosa més. Els atzarosos designis acadèmico-administratius derivats de l'aplicació de la Llei de Reforma Universitària a l'àmbit concret de la Universitat d'Alacant, van fer que les àrees cientffiques d'Estudis Àrabs i Islàmics i de Filologia Catalana quedaren integrades, juntament amb la de Filologia Francesa, en un únic departament - que ha existit fins l'any 1991 - la primera directora del qual va ser, precisament, la professora Rubiera. Aquest fet, d'una o altra manera, va contribuir encara més si cap a la imbricació de la distingida arabista amb la llengua, literatura i cultura catalanes.

Les publicacions de Maria Jesús Rubiera més directament relacionades amb la catalanística es classifiquen en dos grups fonamentals clarament diferenciats: el dels treballs al voltant de les relacions entre la llengua àrab i la catalana i el de les aportacions a l'estudi del Tirant lo Blanc. Tanmateix cal afegir-hi encara una recent comunicació referida a l'autor mallorquí islamitzat Anselm Turmeda (ss. XIV-XV) i dos blocs considerables d'estudis dedicats, respectivament, a la toponímia valenciana $\mathrm{i}$ als orígens de les khartges romàniques en la literatura àrab, entre els quals és facil trobar-ne més d'un directament o indirecta relacionat amb l'àmbit d'estudi propi de la catalanística. El fet, però, que aquestes dues series de publicacions siguen objecte de consideració en altres dues col-laboracions d'aquest Homenatge justifica que em centre acr, sobretot, en les altres aportacions assenyalades.

\section{Les relacions entre l'àrab i el català}

Aquestes relacions han estat estudiades per Maria Jesús Rubiera, fonamentalment, en la ponència que va presentar al IX Col-loqui Internacional de Llengua i Literatura Catalanes (Rubiera 1993b). Cal dir, no obstant, que alguns dels plantejaments i de les tesis que l'autora hi formula ja havien estat anticipats menys desenvolupadament, si més no, en dues ocasions anteriors (Rubiera 1984b i 1987b).

Els estudis de la nostra arabista al voltant d'aquesta temàtica se centren, fonamentalment, en tres aspectes: 
1. El replantejament de la qüestió del "mossàrab", sobretot en allò que toca a la presumpta relació de paternitat d'aquesta llengua amb el valencià.

2. L'establiment de l'extensió i límits de la influència de l'àrab damunt del català $-i$, en especial, de la varietat valenciana d'aquest-, a partir d'una redefinició del concepte d'"arabisme".

3. La formulació de la hipotesi de la possible influència del dialecte valencià de la llengua catalana damunt del dialecte hispano-àrab que es parlava al territori del regne medieval de València.

Pel que fa al primer tema la il-lustre arabista comença per qüestionar l'existència del mossàrab com a llengua neollatina pròpiament dita, atés que una bona part dels trets que la caracteritzen no difereixen dels del llatf vulgar general d'Hispània. És per aixo que Rubiera prefereix parlar, com a molt, d'un proto-romanç d'al-Andalus. De més a més la denominació de mossarab aplicada a aquest protoromanç resultaria inadequada, ja que aquest idioma no va ser privatiu de la minoria homònima de cristians islamitzats, sinó que, ben al contrari, va esdevenir el vehicle d'expressió comú de tota la població d'origen hispànic, amb independència que aquesta s'islamitzara o no.

A partir d'aquestes premises, Maria Jesús Rubiera, d'acord amb el parer dels arabistes més prestigiosos, rebutja de pla la hipotetica filiació de la parla valenciana respecte del "mossàrab" o proto-romanç d'alAndalus, basant-se en tres tipus d'arguments:

a) L'escassa semblança existent entre aquests dos sistemes lingüístics, tret del paregut obvi que els atorga l'ascendencia llatina comuna.

b) L'evidència documental que el "mossàrab" ja havia d'haver desaparegut pels volts del segle XI com a conseqüencia, sobretot, del llarg procés d'arabització d'al-Andalus. En seria un indici fefaent el fet que els veritables mossàrabs de Toledo - nombrós col-lectiu de cristians arabitzats emigrats d'Andalusia - utilitzen l'arab en la documentació que ens han llegat, en comptes de l'hipotètic romanç propi, tot i que aquest seria, sense dubte, molt més pròxim al vehicle d'expressió de la cancelleria toledana o castellana. Per això, dedueix Rubiera (1993b, 305), "si els cristians de Toledo o de Guadix, llocs que sempre s'han considerat centres del mossarabisme, ja no parlaven romanç a Castella, a la fi del segle XI, difícilment el parlarien els de les regions més 
arabitzades com València, Córdova o Sevilla". Per altra banda, els testimonis atesten que, al segle XIII, els musulmans que habitaven el territori valencià escrivien en perfecte àrab clàssic $i$ parlaven en àrab dialectal.

c) L'escàs valor de la toponímia "mossàrab" conservada al País Valencià com a document provatori del manteniment viu d'aquesta llengua fins a temps ben tardans, a causa de la naturalesa arcaitzant $i$ fosilitzant dels toponims de qualsevol llengua.

Quant al segon tema, l'extensió i límits de la influència de l'àrab damunt la llengua catalana, la professora Rubiera sosté una nul la -0 , si de cas, molt minsa - incidencia fonologica, unes mínimes petjades morfosintàctiques - com ara la terminació en - $i$ d'alguns patronímics-, però, en canvi, una empremta lèxico-semàntica molt més significativa, que, a falta encara d'estudis sobre els calcs semàntics, es palesa a bastament en els arabismes lèxics, per bé que aquest siguen molt més abundants en la varietat valenciana del català que no pas en altres dialectes d'aquesta llengua - principati, mallorquí...-. En qualsevol cas cal tenir present la definició d' "arabisme" que proposa i fa servir la nostra homenatjada, segons la qual s'ha d'entendre per tal no sols un manlleu lexic genuïnament àrab incorporat, en aquest cas, al català, sinó qualsevol altre mot que, amb independència de la llengua de procedència originària, haja arribat al català a través de l'àrab, després del corresponent procés d'adaptació fonologica a aquesta última llengua. Així, doncs, el mot català albercoc seria un arabisme perquè, tot i que procedeix originàriament del llatí praecocia, s'incorpora a la llengua catalana a través de la forma birqüq, és a dir, la corresponent adaptació fonologica que l'àrab n'havia fet. Des d'aquesta optica no és pertinent considerar com a llatinismes o "mossarabismes" ( = romancismes) del català alguns mots que, pel fet que no presenten trets d'una evolució romànica ordinària, sinó més bé d'una pura refonologització àrab, no poden ser més que autèntics arabismes d'etiologia llatina o romanç i, en aquest sentit, és important assenyalar que un 10\% del lexic protoromanç d'al-Andalus o "mossàrab" va passar com a manlleu a l'àrab.

Des d'aquests pressupdsits la professora Rubiera estableix les coordenades temporals i espacials en què es produeixen els arabismes del català. En relació amb el temps, la influència de l'àrab sobre el català se circumscriu pràcticament al passat medieval, tret de comptades 
excepcions molt específiques relacionades amb la realitat sòcio-política actual (intiffada, per exemple). La escassa proclivitat vers els arabismes per part d'autors classics llatinitzants, com Joan Roís de Corella, o dels escriptors de la Renaixença -aferrissats sovint a un "purisme" lingüístic exacerbat-, juntament amb la progressiva extinció del món rural que va servir d'escenari a la civilització àrab hispànica, esdevendrien, a parer de la Dra. Rubiera, algunes de les claus d'aquest procés de reculada de l'empremta del lexic àrab sobre el català, procés que, no obstant, la nostra investigadora suggereix d'invertir per via de la introducció de neologismes. Quant al marc geogràfic els arabismes són molt més abundants en la varietat del català pròpia de l'àmbit territorial valencià i aixo, potser, perquè, dins del domini lingüístic de la llengua catalana, va ser a l'antic regne de València on més es va prolongar la convivència o coexistència entre cristians i musulmans (ss. XIII-XVII), a diferència, sense anar més lluny, no ja sols del Principat sinó també de Mallorca, on la població mudéjar va ser molt residual. Precisament, per aquesta raó, la major abundància d'arabismes no sols esdevé un tret peculiar del dialecte valencià, sinó un ajut notable per a esbrinar la procedència geogràfica de textos catalans medievals d'origen o autoria desconeguts o imprecisos (Curial, Tirant...).

Pel que fa als camps a què remeten aquests arabismes, logicament ocupen un lloc rellevant els àmbits més clarament relacionats amb la vida i les activitats dels mudéjars i moriscs, com ara el marítimocomercial (albard, domas, garbl, drassana...), el cientific (dlgebra, alquimia...), el dels oficis tradicionals -especialment els relacionats amb la construcció i l'urbanisme- (rajola, raval, barri...), el de l'administració islàmica (mesquita, alcalde, alfaqut...) o el del món rural (séquia, sénia, assagador...). I això, és clar, sense comptar els topònims, a través del quals, assenyala Rubiera (1993b, 315) amb encert, és possible establir la frontera lingǘstica historica entre el català i el castellà dins del territori valencià, segons el principi lingüístic pel qual els fonemes estrangers són reemesos per l'oient d'acord amb el sistema fonologic propi del seu idioma, de manera que un mot àrab com al-fawwara (=font cabalosa), esdevé Favara en català i Alfaguara en castellà.

L'interés de la professora Rubiera pel tema de les relacions entre la llengua àrab i la catalana, no sols s'ha materialitzat en els estudis 
centrats en la influencia de la primera sobre la segona - especialment en el que afecta a la configuració del dialecte valencià-, sinó que també ha apuntat en la direcció inversa. A aquest proposit cal esmentar la hipòtesi no desenvolupada, però suggerida reiteradament (Rubiera 1984b, 1987b i 1993b), d'una possible influència del catala de l'antic regne de València sobre el dialecte hispano-àrab que es parlava en aquestes terres. La proposta es fonamenta en els quatre segles llargs de convivència d'ambdues parles, que molt bé podria haver possibilitat una interacció recíproca, anàloga a la que es va produir en el cas del dialecte arabigo-granadí $\mathrm{i}$ del castella.

\section{El "Tirant lo Blanc" i l'univers islàmic}

La commemoració el 1990 del cinc-cents aniversari de la publicació de la novel-la cavalleresca valenciana Tirant lo Blanc (1490), va esperonar Maria Jesús Rubiera a encetar una nova línia de recerca al voltant d'aquesta obra des d'una perspectiva araboislàmica. Els fruits d'aquesta dedicació es van materialitzar en una sèrie d'articles (Rubiera 1990a, 1990d, 1991a i 1991d), que, juntament amb diverses conferències $\mathrm{i}$ intervencions congressuals, van preparar el camí del llibre Tirant contra el Islam (Rubiera 1993c), que es pot considerar, per ara, la síntesi de les recerques de la il-lustre arabista sobre aquest tema.

D'entre els múltiples aspectes d'interés que presenta el conjunt dels estudis de Rubiera relacionats amb el Tirant, un, perd, ha reeixit, segurament perquè contribuila a atiar amb nou combustible el foc de la sempiterna polemica de l'autoria de la gran novel la valenciana: $i J o a n o t$ Martorell va ser l'autor únic de l'obra o hi va col'laborar Martí Joan de Galba? En aquest segon cas ¿fins a on arriba la intervenció del primer $i$ on comença la del segon? Maria Jesús Rubiera, com tants altres estudiosos, prova de donar una resposta satisfactoria a aquests interrogants i, per fer-ho, adopta una estratègia metodològica inedita: l'observació de l'univers i dels personatges musulmans que es reflecteix en les diferents zones del Tirant. La conclusió a què arriba és que la configuració literària de l'un i dels altres no és homogènia al llarg de tota la novel·la, sinó, ans al contrari, ben diversa. Així, doncs, mentre que en unes zones de l'obra aquesta palesa un elevat grau de realisme i, per tant, un bon coneixement del món musulmà i dels seus cultemes 
- per bé que només a través dels models mudéjars vius a la societat valenciana del segle $\mathrm{XV}$-, en altres zones s'evidencia una considerable ignorància d'aquest univers a causa dels nombrosos errors i desajustos amb què se'ns configura literàriament. A partir d'això la professora Rubiera dedueix que aquesta dispar presentació literària dels referents islàmics en el Tïrant només es pot explicar per la intervenció de dos autors en la redacció definitiva del text de la novel la tal i com avui el coneixem: un, Martorell, valencià i senyor de propietats poblades per mudéjars, que coneixeria bé la realitat musulmana que tenia a l'abast, i un altre, Galba, català i, per tant, més alié a un coneixement de primera mà d'aquesta mateixa realitat, deficit que es reflectiria en els capitols de l'obra deguts a la seua ploma. Maria Jesús Rubiera situa la línia divisoria de la intervenció substancial d'un i d'altre autor pels volts del capítol 300, venint a coincidir aixf, considerablement, amb la frontera establida per Joan Coromines (1954) i per Antoni Ferrando (1989) a partir de pressuposits estilístics i lingüístics. Tanmateix, mentre que en un primer moment la nostra arabista (Rubiera 1990d) atribueix a Galba la paternitat íntegra de la novel-la des d'aquest capítol fins a la fi, posteriorment (Rubiera 1993c) limita la intervenció bàsica de l'hipotètic co-autor català als capítols compresos entre el 300 i el 350 i atorga a Martorell la responsabilitat substancial de tota la resta. Aquest canvi es deu al fet que una relectura més detinguda de l'obra - probablement esperonada per la rèplica d'algun altre estudiós (Chiner 1991)permet a Rubiera retrobar, en els capítols posteriors al 350, una plasmació de bell nou fidedigna de l'univers islàmic i, per tant, al seu parer, martorelliana.

Perd, tot i que la teoria que acabem de resumir ha esdevingut l'aportació més reeixida dels estudis de la nostra arabista sobre el Tirant, no és l'única que ens ha llegat en relació amb aquest tema. Així doncs, i entre altres aspectes d'interés, cal destacar el replantejament del tema de les fonts literàries orientals de la novel-la valenciana, formulat inicialment per Siegfried Bosch (1949-50), per a qui el Tirant hauria rebut la influencia de la novel-la cavalleresca àrab (=sira) Umar anNuman, inserida en Les mil $i$ una nits, amb la qual presenta una sèrie de concomitàncies temàtiques i situacionals considerables. Maria Jesús Rubiera qüestiona, en primer lloc, el vehicle de transmissió textual proposat per Bosch, les relacions militars i comercials catalano- 
aragoneses amb l'Orient durant la baixa Edad Mitjana, atés que no hi han indicis de la vessant literària d'aquestes relacions. Sf que és més factible, tanmateix, explicar l'empremta aràbigo-oriental com a resultat de la llarga presencia de l'Islam en la península (ss. VIII-XVII) i de l'assimilació europea d'elements literaris orientals a través de les traduccions al llatr $i$ a les llengües vulgars realitzades a l'ambit hispànic entre els segles XII i XIV. Però, de més a més, Rubiera aporta un argument decisiu en contra d'una influència directa d'Umar sobre el Tirant: que el relat cavalleresc àrab adduït per Bosch no apareix en els testimonis més antics de Les mil i una nits (edició de Leiden, 1984), ja que només es va incorporar a l'obra a partir del segle XVI. L'obra valenciana, doncs, no presentaria intertextualitats de l'àrab, sinó pures coincidències o concomitàncies.

Quelcom semblant s'esdevé, segons Rubiera, amb un segon component textual tirantia habitualment relacionat amb Les mil i una nits, la famosa història del filosof de Calàbria inserida al capítol 110. Si bé és cert que en trobem un testimoni molt semblant en Les mil i una nits, cal tenir en compte -ens alerta l'arabista - que aixo només es produeix en la molt reelaborada versió francesa de l'obra preparada pel metge cairota Mardrus (1868-1949) i no en els textos corresponents de la vulgata. És, doncs, més facil pensar que la historieta del filosof haja arribat al Tirant a través dels testimonis romànics que en trobem al Novellino italià (s. XIII) o al Libro de los enxemplos castellà de Clemente Sánchez de Vercial (ss. XIV-XV) i això, sense perjudici, és clar, d'un més que probable model àrab, en forma de conte, al qual remetrien, en última instància, les diverses reformulacions romàniques $i$, fins i tot, la reelaboració tardana que trobem a Les mil $i$ una nits. Un procés anàleg s'hauria produït en l'episodi de l'engany de la Viuda Reposada per fer creure a Tirant que Carmesina li és infidel amb el negre hortolà Lauseta, que, tot i arribar a la novel-la valenciana a través de les Novelle italianes de Giovanni Sercambi (ss. XIV-XV), remetria, al capdavall, a Les mil $i$ una nits.

Per a Maria Jesús Rubiera, doncs, la influència literària aràbigooriental en el Tirant lo Blanc no és especialment rellevant i, en tot cas, mai no és produeix d'una manera directa, sinó a través de fonts occidentals que han assumit prèviament les empremtes orientals. 


\section{Altres aportacions a la catalanística}

Un altre text català que ha estat objecte d'atenció de la professora Rubiera és la narració al-legorica en vers Cobles de la divisió del regne de Mallorca, escrita a Tunis el 1398 pel francisca mallorqui islamitzat Anselm Turmeda. Aquest autor és un clar exponent de sincretisme cultural aràbigo-català $i$, com a tal, va escriure obres en una i altra llengua a partir de models $\mathrm{i}$ fonts de les dues cultures. Maria Jesús Rubiera (1993a) proposa com a possible model de les Cobles una font àrab: un exemplum inserit en un sermó propi del ritu de rogatives de pluja, preservat a través d'una traducció aljamiada l'original de la qual potser Turmeda va escoltar a Tunis. En tots dos textos, l'àrab i el turmedià, a més d'algunes analogies de caire escenogràfic, una regina esdevé l'element central de la narració i s'hi dóna un cert paralel·lisme argumental: en els dos casos els habitants d'un poble pateixen una situació negativa a causa de les seues iniquitats, situació només superable mitjançant el penediment dels pecats que possibilitarà la restitució del primitiu ordre harmònic perdut.

Sense perjudici de la concurrència d'altres models $i$ fonts en les Cobles turmedianes pertanyents a la tradició cristiano-occidental i, més concretament, a la catalana (Badia 1993), la proposta de Rubiera és digna de consideració $i$, per suposat, possible, atés que Turmeda ja havia begut en fonts àrabs en altres ocasions -i no sols en la Tuhfa, l'única obra islàmica de l'autor-, com ara en la Disputa de l'ase, tal i com tots sabem d'ençà que M. Asín Palacios (1914) en descobrira l'original. Per altra banda, aquesta hipòtesi pren encara més força si tenim en compte que el deute de les Cobles amb l'estètica àrab es fa també clarament perceptible a través d'una reiterada presència de recursos plastico-sensorials, gens ni mica habitual en altres textos catalans afins (Samsó 1971-1972).

No seria just cloure aquesta limitadíssima ressenya dels estudis de catalanística de la professora Rubiera sense, si més no, al-ludir a la revisió de la tesi "canònica" - la fixada per Menéndez Pidal- sobre l'origen de les khartges de les muwašahes arabs: la nostra investigadora, a partir d'una reformulació de les propostes de Julià Ribera, es mostra contrària a una descodificació mossàrab d'aquestes exclusiva i excloent, pel fet que alguns d'aquests petits poemets admeten lectures 
més plausibles en altres llengües romàniques, com ara l'occità o el català. Les khartges, doncs, podrien tenir una procedencia romànica d'abast ampli i divers, alhora que haurien arribat a Al-Andalus a través de les esclaves gallegues o de les de l'àmbit francés, occità o català (Rubiera 1987a, 1988, 1989a, 1989b, 1990b, 1990c, 1991c).

Però tant aquesta darrera qüestió com la de la toponímia aràbigocatalana -especialment l'arabigo-valenciana- (Rubiera 1982, 1983a, 1983b, 1984a, 1984c, 1985, 1989c, 1991b, 1992b i Rubiera/Epalza 1985 i 1986), ultrapassen el marc estricte de la catalanística i, a més, són objecte de consideració monogràfica en altres collaboracions d'aquest mateix volum. Per aquesta raó no me n'ocupe acr, com tampoc ho faig d'algun que altre treball de l'autora de caire més circumstancial (Rubiera 1992a).

\section{Conclusió}

Comptat i debatut, ens trobem davant d'una aportació a la catalanística metodologicament original - feta des de la talaia de l'arabisme-, quantitativament abundant i temàticament diversa, però, sobretot, farcida de suggerències i d'hipòtesis alternatives, en algun cas agosarades, que poden provocar l'adhesió o la polemica fructffera, pero mai no caure en la indiferència. I aixd no és poca cosa.

\section{REFERENCIES BIBLIOGRÀFIQUES}

Asín Palacios, Miguel (1914), "El original árabe de la Disputa del Asno contra fr. Anselmo Turmeda", Revista de Filologia Española, I, pp. 1-51.

BADIA, Lola (1993), "De la Faula al Tirant, passant, sobretot, pel Llibre de Fortuna e Prudència" ${ }^{n}$, dins Tradició i modernitat als segles XIV $i \mathrm{XV}$. Estudis de cultura literària $i$ lectures d'Ausiàs March, València/Barcelona, Institut de Filologia Valenciana/Publicacions de l'Abadia de Montserrat, pp. 93-128.

Bosch, Siegfried (1949-50), "Les fonts orientals del Tirant lo Blanc", Estudis Romànics, 2, pp. 1-50.

Chiner GMeno, Jaume Josep (1991), "Batalla a ultrança per Joanot Martorell", A Sol Post. Estudis de Llengua i Literatura (Alcoi, Alacant), 2, pp. 83-127. 
Coromines, Joan (1954), "Sobre l'estil i manera de Martí Joan de Galba i el de Joanot Martorell", dins Homenatge a Carles Riba en complir seixanta anys, Barcelona, pp. 168-184. [Reed. dins Lleure $i$ converses d'un fildleg, Barcelona, 1971, pp. 363-378].

FERRANDO, Antoni (1989), "Entorn de la llengua del Tirant lo Blanc", Saó, València, febrer, pp. 24-26.

Rubiera Mata, María Jesús (1982), "Significado de algunos topónimos árabes de Aspe", La Serranica (Aspe), 36, pp. 17-18. (Elda), XXIX.

(1983a), "Elda en el campo de Tudmir: camino y fortaleza", Alborada

(1983b), "Aspe, la gran calzada y el camino de la Almohaja", La Serranica (Aspe), 37.

(1984a), "Rafals y raales; ravals y arrabales; reals y reales", Sharq $\mathrm{Al}$ Andalus. Estudios Árabes (Universidat d'Alacant), 1, pp. 117-122.

(1984b), "Precisiones sobre los dialectos arábigo-granadino y arábigovalenciano", Sharq Al-Andalus. Estudios Árabes (Universitat d'Alacant), 1, pp. 151-152.

(1984c), "Toponimia arábigo-valenciana: falsos antropónimos beréberes", Miscel-lània Sanchis Guarner. Quaderns de Filologia, I, València, Universitat de València, pp. 317-320. Villena/Universidad de Alicante.

i Míkel de Epalza (1985), Els noms àrabs de Benidorm i la seua comarca, Ajuntament de Benidorm-Universitat d'Alacant. [Hi ha versió castellana del mateix any].

i Míkel de Epalza (1986), "Estat actual dels estudis de toponímia valenciana d'origen àrab", X Col-loqui General de la Societat d'Onomàstica, València, pp. 420-426.

(1987a), "La lengua romance de las jarchas (una jarcha en lengua occitana)", Al-Qanțara (Madrid), 8, pp. 319-329.

(1987b), "La lengua árabe y la lengua valenciana", Las lenguas prevalencianas, Universidad de Alicante, pp. 93-95.

(1988), "Nueva aproximación al estudio literario de las jarchas andalusies", Sharq Al-Andalus. Estudios Arabes, 5, pp. 89-100.

(1989a), "Relacions d'anada i tornada entre la poesia provençal i la poesia àrab a través dels catalans: kharges en llengua occitana", Actes del Vuitè Col-loqui Internacional de Llengua i Literatura Catalanes, I, Barcelona, Publicacions de l'Abadia de Montserrat, pp. 237-244.

(1989b), "Cançonetes de tipus kharja en la literatura catalana", Miscel-lània Joan Fuster. Estudis de llengua i literatura, I, Barcelona, Publicacions de l'Abadia de Montserrat, pp. 1-8. 
$(1989 \mathrm{c})$, "Els topònims aràbigo-catalans del Baix Segura (Alacant)", Sharq Al-Andalus. Estudios Árabes, 6, pp. 159-160.

(1990a), "El món cavalleresc àrab i el món cavalleresc del Tirant", Afers.

Fulls de recerca i pensament (Catarroja, València), V, 10, pp. 267-274.

(1990b), "Una fórmula elocutiva en la lírica tradicional romànica i una altra possible khartja occitana", A Sol Post. Estudis de llengua i literatura (Alcoi, Alacant), 1, pp. 193-196.

(1990c), "Una nueva hipótesis sobre la lengua de las jarchas a partir de las investigaciones de Rafael Lapesa", Homenaje al Profesor Lapesa, Universidad de Murcia, pp. 227-232.

(1990d), "Tirant lo Blanc i els moros", L'Aiguadolc. Revista de literatura (la Marina Alta, Alacant), 12-13, tardor, pp. 33-40.

(1991a), "El Tirant i la literatura àrab", Serra d'Or (Montserrat), 371, novembre, pp. $57-58$.

(1991b), "Els camins àrabs de la muntanya i la marina alacantines i una hipòtesi sobre el nom d'Alcoi", Societat d'Onomàstica. Butlleti Interior: XIVè Col.loqui, 44, II, pp. 671-672.

(1991c), "Presencia románica extra-andalusí en las jarchas", Actas del Primer Congreso Internacional sobre poesía estrofica arabe y hebrea y sus paralelos romances, Madrid, Facultad de Filología de la Universidad Complutense-Instituto de Cooperación con el Mundo Árabe, pp. 289-295.

to de Novelda, pp. 25-30.

(1991d), "Tirant lo Blanc i els moros", Moros y Cristianos, Ayuntamien-

(1992a), "Joan Fuster y la poesía árabe", Sharq Al-Andalus. Estudios Árabes (Universidad de Alicante), 9, pp. 89-92.

(1992b), "Toponímia àrabo-valenciana: falsos antropònims berbers", Miscel-lània Sanchis Guarner, III, Barcelona, Publicacions de l'Abadia de Montserrat, pp. 157-166.

(1993a), "Una possible font àrab de l'estructura argumental de les Cobles de la divisió del Regne de Mallorca", Actes del Nové Col-loqui Internacional de Llengua i Literatura Catalanes (Alacant-Elx, 9-14 de setembre de 1991), I, Barcelona, Publicacions de l'Abadia de Montserrat, pp. 161-166.

(1993b), "Els arabismes del català. Història d'un rebuig", Actes del Nové Col-loqui Internacional de Llengua i Literatura Catalanes (Alacant-Elx, 9-14 de setembre de 1991), II, Barcelona, Publicacions de l'Abadia de Montserrat, pp. 301-317.

(1993c), Tirant contra el lslam, Altea (Alicante), Ediciones Aitana.

SAMSÓ, Julio (1971-1972), "Turmediana", Boletín de la Real Academia de Buenas Letras de Barcelona, XXIV, pp. 72-75. 